\title{
HA Filler Injection and Skin Quality-Literature Minireview and Injection Techniques
}

\author{
Jui-Hui Peng ${ }^{1}$ Peter Hsien-Li Peng, ${ }^{2, \odot}$ \\ ${ }^{1}$ Kaohsiung Armed Forces General Hospital, Kaohsiung, Taiwan \\ 2p-Skin Professional Clinic, Kaohsiung, Taiwan
}

\author{
Address for correspondence Peter Hsien-Li Peng, MD, P-Skin \\ Professional Clinic, Kaohsiung 813, Taiwan \\ (e-mail: pengskin@gmail.com).
}

Indian J Plast Surg:2020;53:198-206

\begin{abstract}
Keywords

- static wrinkles

- radial cheek lines

- skin quality

- HA filler injection

- skin rejuvenation

Aging of the face produces many changes in the structure and integrity of the skin and other anatomical aspects, the three major signs of which are volume loss, sagginess, and skin quality change. Through surgical or nonsurgical procedures, it is possible to slow or even reverse these mechanisms through artificial means, including thread lifting, radiofrequency, or filler injection. Filler injections are particularly popular in recent years, owing to their convenience, efficacy, and long-lasting results. In this minireview, the author outlines the basic mechanisms behind facial aging, discusses current literature on each aspect of facial aging, and offers injection protocol recommendations based on past literature and clinical experience.
\end{abstract}

\section{Introduction}

The aging face can greatly impact an individual's appearance and confidence. There are three major signs of an aging face: volume loss, sagginess, and skin quality change, for example, atrophy and laxity. Cosmetic intervention to the aging face includes surgical and nonsurgical approaches, of which there are a wide variety of options available, including lasers and energy-based devices (EBDs), cosmeceuticals, topical medications, botulinum toxin injections, thread insertions, and filler injections.

There are numerous well-studied signs of the aging face. In the upper face, expression lines may become more prominent, there may be signs of ptotic eyebrows and upper eyelids, and eye bags may form. In the midface, the lid-cheek junction may become elongated, cheeks may experience sagging, nasolabial folds may become more prominent, and the midface region may experience pronounced volume loss. In the lower face, tissue sagging may become more evident, and jowls may form along the jawline, contributing to its irregularity. These clinical findings may be related to the underlying changes in bony structure support, ${ }^{1}$ (-Fig. 1) fat compartments, ${ }^{23}$ mimetic muscles, and skin. ${ }^{4}$ Laxity in the superficial muscular aponeurosis system (SMAS) and retaining ligaments ${ }^{5}$ may also be contributing factors. - Fig. 2 shows the five layers of the face. ${ }^{6}$
These signs of aging are common targets of aesthetic correction. Currently, there are a wide variety of options available for treatment, such as lasers and EBDs (including monopolar and bipolar radiofrequency [RF], high-intensity focused ultrasound [HIFU], and the picosecond laser with fractional hand-piece, etc.), cosmeceuticals with clinically-effective active ingredients, topical medications (such as retinoic acid), botulinum toxin injections, thread insertions, and filler injections. Various injectable filler material, such as poly-L-lactic acid (PLLA), hyaluronic acid (HA), and hydroxylapatite, have shown the ability to induce new collagen formation after injection, thereby improving skin thickness or skin quality. ${ }^{7-13}$ In this short review, the author will examine the current evidence and possibilities for treatment, and draw from personal experience to formulate expert recommendations, focusing on HA filler injections in particular.

\section{Methods}

Various injectable filler material, such as PLLA, HA, and hydroxylapatite, have shown the ability to induce new collagen formation after injection, thereby improving skin thickness or skin quality. In this short review, the author will examine the current evidence and possibilities for treatment, and draw from personal experience to formulate expert
License terms

(요 $\Theta \circledast$ 


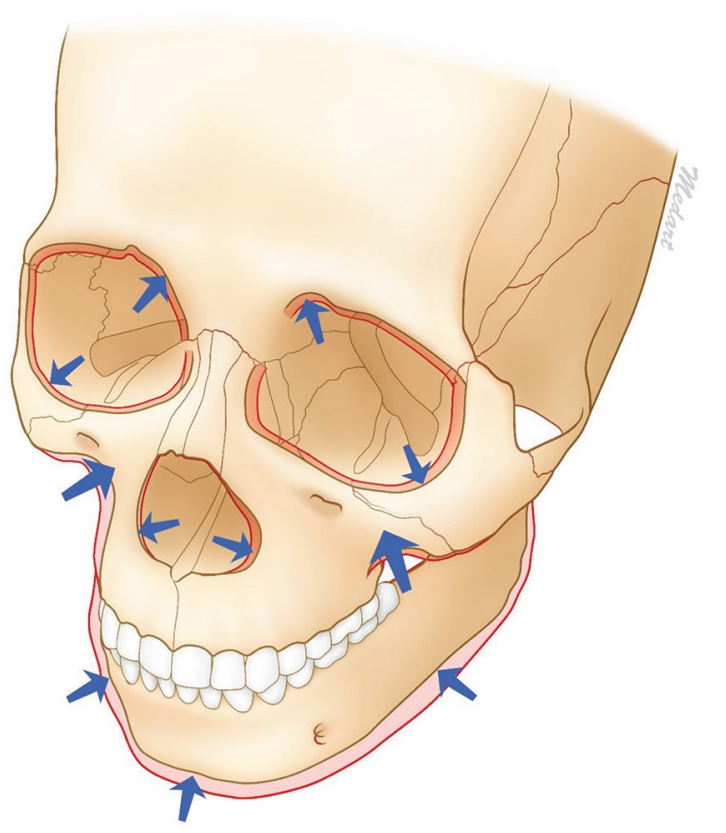

Fig. 1 Bony remodeling in aging. (Kim HJ, et al. Clinical anatomy of the face for filler and botulinum toxin injection, Springer 2016, ${ }^{6}$ with kind permission from Dr. Kim.)

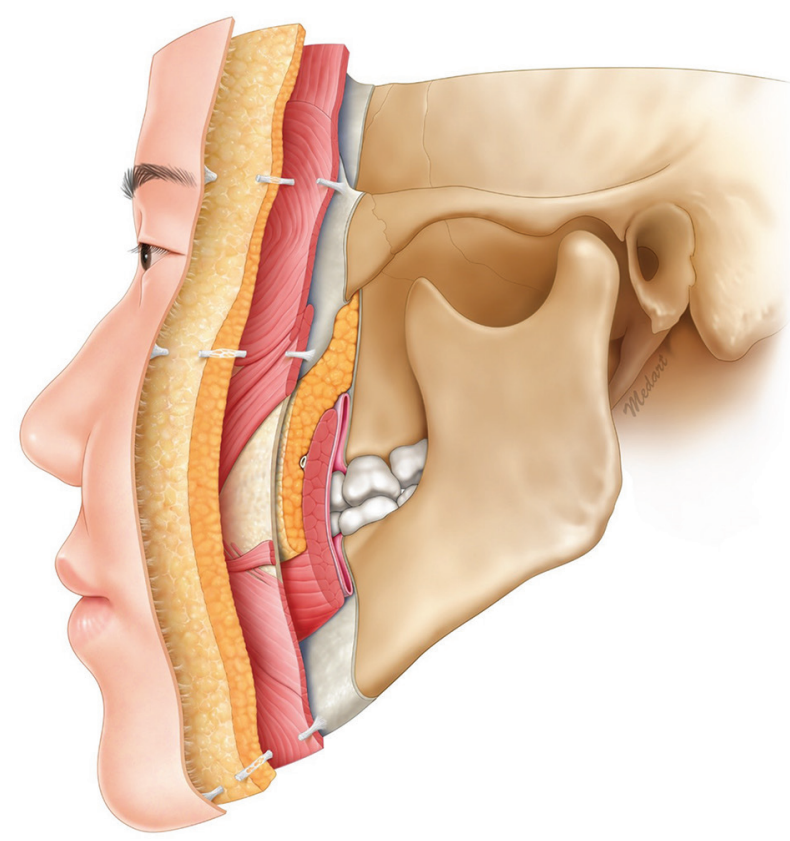

Fig. 2 The five facial layers. Layers 1 to 5 , ranging from superficial to deep, are as follows: Skin (epidermis and dermis); Subcutaneous layer (superficial fat); Facial muscles and SMAS; Retaining ligaments and spaces (deep fat); and Periosteum and deep fascia. (Kim HJ, et al. Clinical anatomy of the face for filler and botulinum toxin injection, Springer 2016, ${ }^{6}$ with kind permission from Dr. Kim.). Abbreviations: SMAS, superficial musculoaponeurotic system.

recommendations, focusing on HA filler injection to improve skin quality.
As this is not a systematic review, the references cited are not intended to be results from an exhaustive search. Three specific signs of the aging skin-static wrinkles, radial cheek lines, and deteriorating skin quality-will be the focus of discussion, with the review divided into these respective sections, following a section on HA filler injection techniques. For each section, the appropriate literature will be outlined and discussed, followed by the author's personal recommendations from over two decades of clinical experience.

\section{Results and Discussion}

\section{Treatment Options for the Aging Face}

As previously mentioned, there are multiple techniques available to treat the aging face. Surgery, especially facelift surgery (rhytidectomy), has traditionally been considered the treatment of choice, although in recent years, minimal invasive approaches (including lasers and EBDs, cosmeceuticals, topical medications, chemical peeling, botulinum toxin injections, suspension threads, and filler injections) have evolved to become the more commonly-performed procedures. Quite often these modalities are introduced in combination for synergistic effects through different mechanisms or modes of action, targeting different pathophysiological aspects of the aging processes. - Table $\mathbf{1}$ shows the summary of treatment options for the aging face.

\section{Filler Injection}

Filler injections have become quite popular in the past two decades by virtue of its instant efficacy, high-safety profile, and accessibility. Filler correction is capable of accomplishing many of the same results as surgical correction: "lifting" to improve cheek laxity; $1^{4,15}$ "contouring" of the nose, chin, and forehead; $1^{6}$ "volumization" over areas of bony loss or deficiency, or areas of deep fat atrophy,

Table 1 Treatment strategies for correction of facial aging (modified from Bohnert et $\mathrm{al}^{9}$ )

\begin{tabular}{|c|c|c|}
\hline $\begin{array}{l}\text { Key aging } \\
\text { signs }\end{array}$ & $\begin{array}{l}\text { Surgical } \\
\text { approaches }\end{array}$ & Nonsurgical approaches \\
\hline \multirow[t]{2}{*}{ Volume loss } & Fat graft & Filler injections \\
\hline & Implants & \\
\hline \multirow[t]{3}{*}{ Sagginess } & Face/neck lift & Suspension threads \\
\hline & & $\begin{array}{l}\text { EBDs (monopolar RF, } \\
\text { HIFU, etc.) }\end{array}$ \\
\hline & & Filler injection \\
\hline \multirow[t]{5}{*}{$\begin{array}{l}\text { Skin } \\
\text { rejuvenation }\end{array}$} & $\begin{array}{l}\text { Laser } \\
\text { resurfacing }\end{array}$ & Fractional lasers \\
\hline & $\begin{array}{l}\text { Chemical } \\
\text { peeling }\end{array}$ & $\begin{array}{l}\text { Picolaser with fractional } \\
\text { handpiece }\end{array}$ \\
\hline & & Microneedling RF, Bipolar RF \\
\hline & & Topical medications \\
\hline & & Cosmoceuticals \\
\hline
\end{tabular}

Abbreviations: EBD, energy-based devices; RF, radiofrequency; HIFU, high-intensity focused ultrasound. 
such as the deep malar fat pads or superficial fat pads; $1^{7}$ "general improvement" of multifaceted anatomical problems such as the tear trough deformity complicated with eye bags, ${ }^{18}$ static wrinkles, ${ }^{19}$ or cheek lines ${ }^{20}$; and "rejuvenation" effects that lead to increased skin quality and thickness. ${ }^{7,8,9,21}$

Different kinds of filler injections include permanent fillers and absorbable fillers. Permanent fillers, for example, silicone-based products can last more than 6 years. Absorbable fillers, which include PLLA (Sculptra, Galderma), hydroxylapatite (Radiesse, Merz), polycaprolactone (PCL; Ellansé, Sinclair), and HA, can last anywhere from 9 months to over 2 years, depending on type and location. Owing to multiple reports of long-term complications of permanent fillers, practitioners tend to favor long-lasting but absorbable substances as their filler of choice. Globally, HA fillers are the most commonly used. ${ }^{22}$ Injection techniques also vary according to clinical indication, patient condition, and desired end result. - Table 2 summarizes reported injection techniques used for HA filler injection.

\section{Aging Skin}

Factors influencing skin aging can be categorized based on etiology. Innate, genetically predetermined conditions are known as intrinsic factors, while exogenous causes such as air pollution, smoking, nutrition, sleep, and electromagnetic radiation from sun exposure-ultraviolet (UV) light, blue light, infrared light-are known as extrinsic factors. ${ }^{4}$ The process of skin aging begins with an initial "dryness," which leads to the appearance of fine superficial facial lines,

Table 2 Commonly-used HA filler injection techniques (Modified from ${ }^{17,18,23,24,2526}$ )

\begin{tabular}{|l|l|l|}
\hline \multirow{2}{*}{ Technique } & Subtype & Remark \\
\hline & Small bolus & $0.3 \mathrm{ml}$ per injection \\
\cline { 2 - 3 } & Aliquot & $0.1-0.2 \mathrm{ml}$ \\
\cline { 2 - 3 } Serial puncture & Micro-aliquot & $\begin{array}{l}0.01-0.05 \mathrm{ml} \text { per } \\
\text { point }\end{array}$ \\
\hline Tower technique & & \\
\hline $\begin{array}{l}\text { Blanching } \\
\text { technique }\end{array}$ & & $\begin{array}{l}\text { Useful for static } \\
\text { wrinkles }\end{array}$ \\
\hline Linear (threading) & Antegrade & \\
\cline { 2 - 3 } & Retrograde & $\begin{array}{l}\text { Useful for nasolabial } \\
\text { folds }\end{array}$ \\
\hline Fern pattern & & \\
\hline Fanning & & $\begin{array}{l}\text { As multiple } \\
\text { cross-hatching }\end{array}$ \\
\hline Cross-hatching & & \\
\hline Grid & & \\
\hline Layering & & \\
\hline $\begin{array}{l}\text { Subcision/ } \\
\text { tunneling }\end{array}$ & & \\
\hline
\end{tabular}

followed finally by the loss of skin tone and increased skin laxity. Histological studies on aging showed atrophy of epidermis and dermis, loss of dermal-epidermal junction ridges, decreased number of blood and lymphatic vessels, decreased number of skin appendages, and loss of collagen and elastin fibers. - Table 3 shows a summary on the various structural changes in the aging skin. ${ }^{27}$

Mechanical properties of the skin and their aging-associated changes are one of the first objectively measurable metrics used to indicate the degree of aging. ${ }^{28}$ As the skin ages, it becomes more lax, less elastic, and less thick. Aside from the impact on skin quality and facial shape, skin laxity influences the formation of wrinkles: facial mimetic muscles can mold and shape the overlying skin to form dynamic wrinkles, which gradually become static visible lines, or static wrinkles, in the event of decreased dermal support and increased laxity. Wrinkles have long been associated aesthetically with age: a study in Chinese populations have demonstrated that the presence of wrinkles invariably made subjects appear older than identically aged controls according to observers. ${ }^{29}$

This change in mechanical property is the result of the quality, abundance, and distribution of the major dermal components that influence skin elasticity, turgidity, and resilience, namely, collagen fibers, elastin fibers, and HA. The fragmentation of collagen and elastin fibers in aging skin causes less stretching of skin fibroblasts, which results in less

Table 3 Structural changes in the aging skin. (Modified from Farage et $\mathrm{al}^{27}$ )

\begin{tabular}{|c|c|}
\hline Layer & Observed effect of aging \\
\hline $\begin{array}{l}\text { Stratum } \\
\text { corneum }\end{array}$ & Lower lipid content \\
\hline \multirow[t]{5}{*}{ Epidermis } & Dermal-epidermal junction flattens \\
\hline & $\begin{array}{l}\text { Number of enzymatically active melanocytes } \\
\text { decreases by } 8 \text { to } 20 \% \text { per decade }\end{array}$ \\
\hline & Number of Langerhans cells decrease \\
\hline & Capacity for re-epithelization diminishes \\
\hline & Number of pores increase \\
\hline \multirow[t]{8}{*}{ Dermis } & Thickness reduced (atrophy) \\
\hline & Vascularity and cellularity decrease \\
\hline & Collagen synthesis decrease \\
\hline & Pacinian and Meissner's corpuscles degenerate \\
\hline & $\begin{array}{l}\text { Structure of sweat glands become distorted, and } \\
\text { number of functional sweat glands decrease }\end{array}$ \\
\hline & Elastic fiber degrades \\
\hline & Number of blood vessels decrease \\
\hline & Number of nerve endings reduce \\
\hline \multirow[t]{2}{*}{ Hypodermis } & Distribution of subcutaneous fat changes \\
\hline & Overall volume decrease \\
\hline \multirow[t]{5}{*}{ Appendages } & Hair loses normal pigments \\
\hline & Hair thins \\
\hline & Number of sweat glands decrease \\
\hline & Nail plates become abnormal \\
\hline & Sebum production reduced \\
\hline
\end{tabular}


production of new collagen and elastic fibers, leading to the overall decrease in skin quality.

\section{Static Wrinkles}

Dynamic lines such as forehead lines, glabela lines, and crow's feet see substantial improvement after treatment by botulinum toxin, given careful positioning and deposition of product. ${ }^{30}$ Static wrinkles, on the other hand, are permanent, structural anatomical alterations, making neurotoxic agents such as botulinum toxins much less effective. Instead, other modalities might be used, such as EBDs, skin tightening devices, or filler injection, for which reconstituted HA has produced satisfactory results. ${ }^{19}$

The injection technique for the HA treatment of wrinkles has been described by numerous authors, which generally consists of utilizing serial puncture techniques over static wrinkles with tiny amounts of reconstituted HA filler. Static wrinkles over the forehead, glabela, periorbital, and perioral areas can all be treated using this technique. The specific details of injection sequences vary in accordance with authors. For example, one article recommended injection into the superficial dermis with a specially designed, less concentrated HA product, and a blanching technique for the improvement of static wrinkles. ${ }^{26}$ Another article recommended a method of "Skinboosting" for static wrinkles: nonanimal stabilized HA (NASHA) 20 mg (Restylane Vital, Galderma) or $12 \mathrm{mg}$ (Restylane Vital light, Galderma), injected with 30G needles through serial puncture. ${ }^{10}$

\section{Author Preference}

For static wrinkles, based on clinical experience, the author prefers VYC-15L HA (Juvéderm Volbella, Allergan) injected through 31 to 33G needles in the superficial dermal layer, with the serial puncture method depositing approximately 0.005 $\mathrm{mL}$ per injection. Immediate molding with cotton stick after injection is preferred. - Table 4 shows the summary of the author's preferences for injection techniques for static wrinkle treatment. - Fig. 3 shows an example of static wrinkles over the left cheek treated by this technique. - Figs. 4 and $\mathbf{5}$ show examples of static wrinkles (forehead and glabela, respectively) after combination treatment with botulinum

Table 4 Author preference for the treatment of static wrinkles

\begin{tabular}{|l|l|}
\hline Items & Suggestion \\
\hline $\begin{array}{l}\text { Type of HA } \\
\text { product }\end{array}$ & $\begin{array}{l}\text { Vycross } 15 \mathrm{mg} / \mathrm{mL} \mathrm{HA} \text {; VYC-15L (Juvéderm } \\
\text { Volbella, Allergan) }\end{array}$ \\
\hline Injection layer & $\begin{array}{l}\text { Deep intradermal to superficial subdermal } \\
\text { injection }\end{array}$ \\
\hline Injection tool & $31-33 \mathrm{G}$ needle \\
\hline $\begin{array}{l}\text { Injection } \\
\text { technique }\end{array}$ & Microdroplet (micro-aliquot) \\
\hline $\begin{array}{l}\text { Injection } \\
\text { amount }\end{array}$ & $0.005 \mathrm{~mL}$ per injection every $2 \mathrm{~mm}$ \\
\hline Note & $\begin{array}{l}\text { Molding with cream may help better tissue } \\
\text { integration. }\end{array}$ \\
\hline
\end{tabular}

Abbreviation: HA, hyaluronic acid.
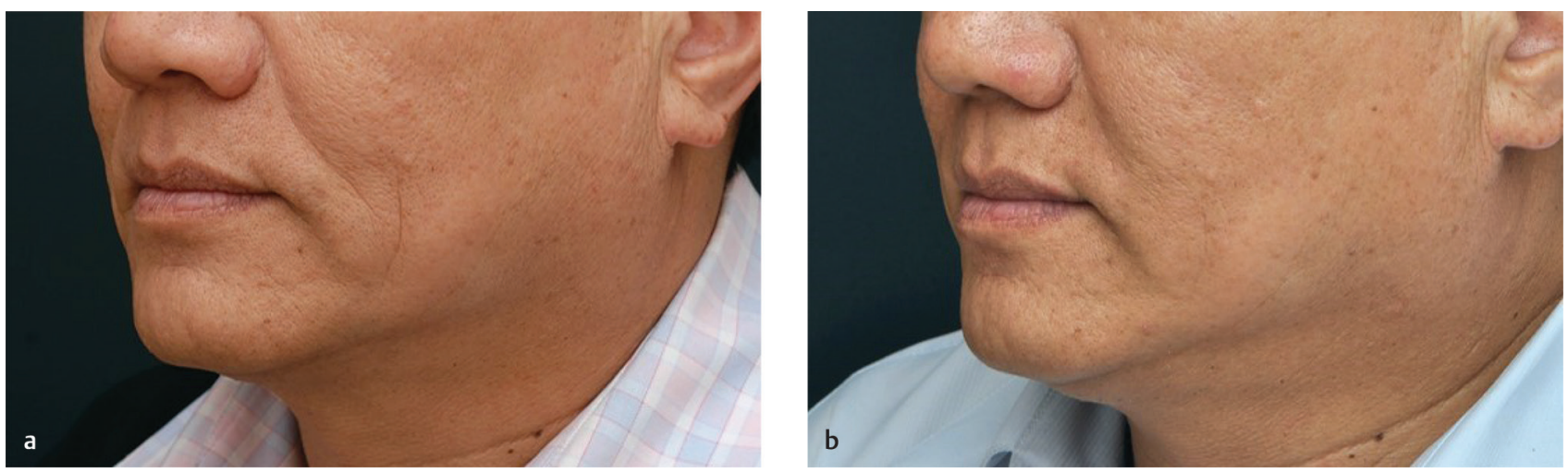

Fig. 3 Static radial cheek lines. (a) Before treatment. (b) 2 months after serial puncture injection with VYC-15L (Juvéderm Volbella, Allergan), $0.2 \mathrm{~mL}$ per side.
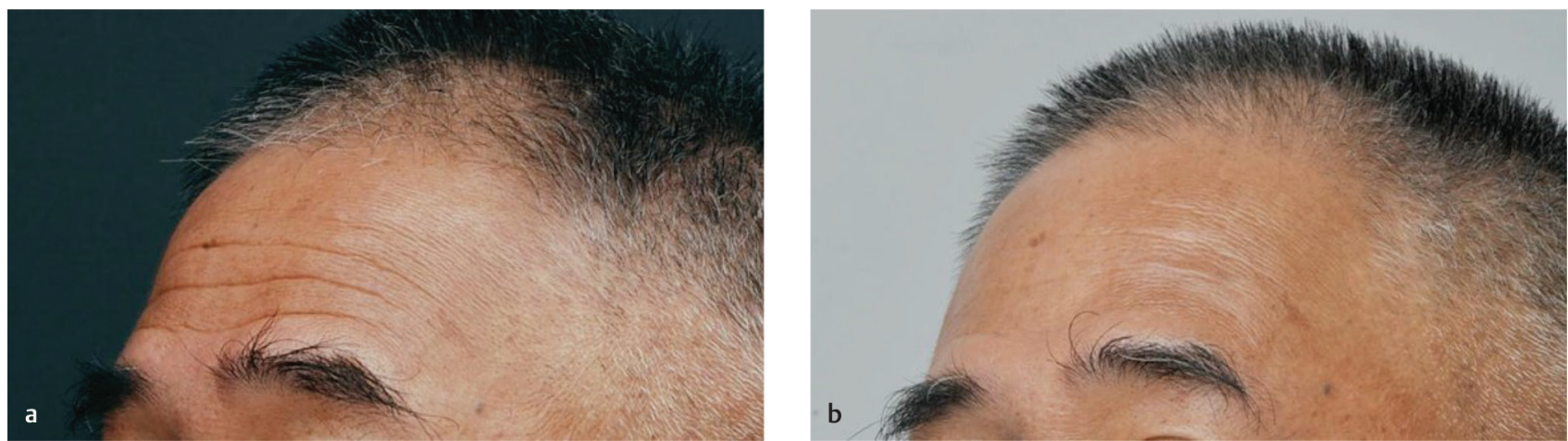

Fig. 4 Static wrinkles over the forehead. (a) Before treatment. (b) 14 months after injection with VYC-15L (Juvéderm Volbella). Significant efficacy is still present. Also, note the improved skin quality. 

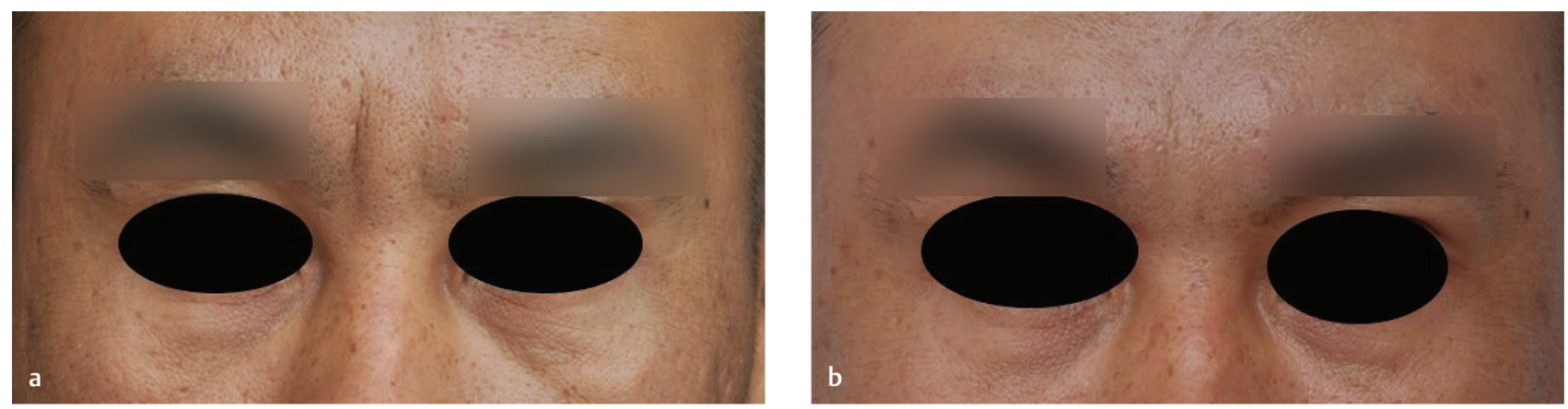

Fig. 5 Static wrinkles over the glabela. (a) Before treatment. (b) After injection with botulinum toxin 20 unit and $0.5 \mathrm{ml}$ of VYC-15L HA (Juvéderm Volbella, Allergan) with needle, using the serial puncture technique.
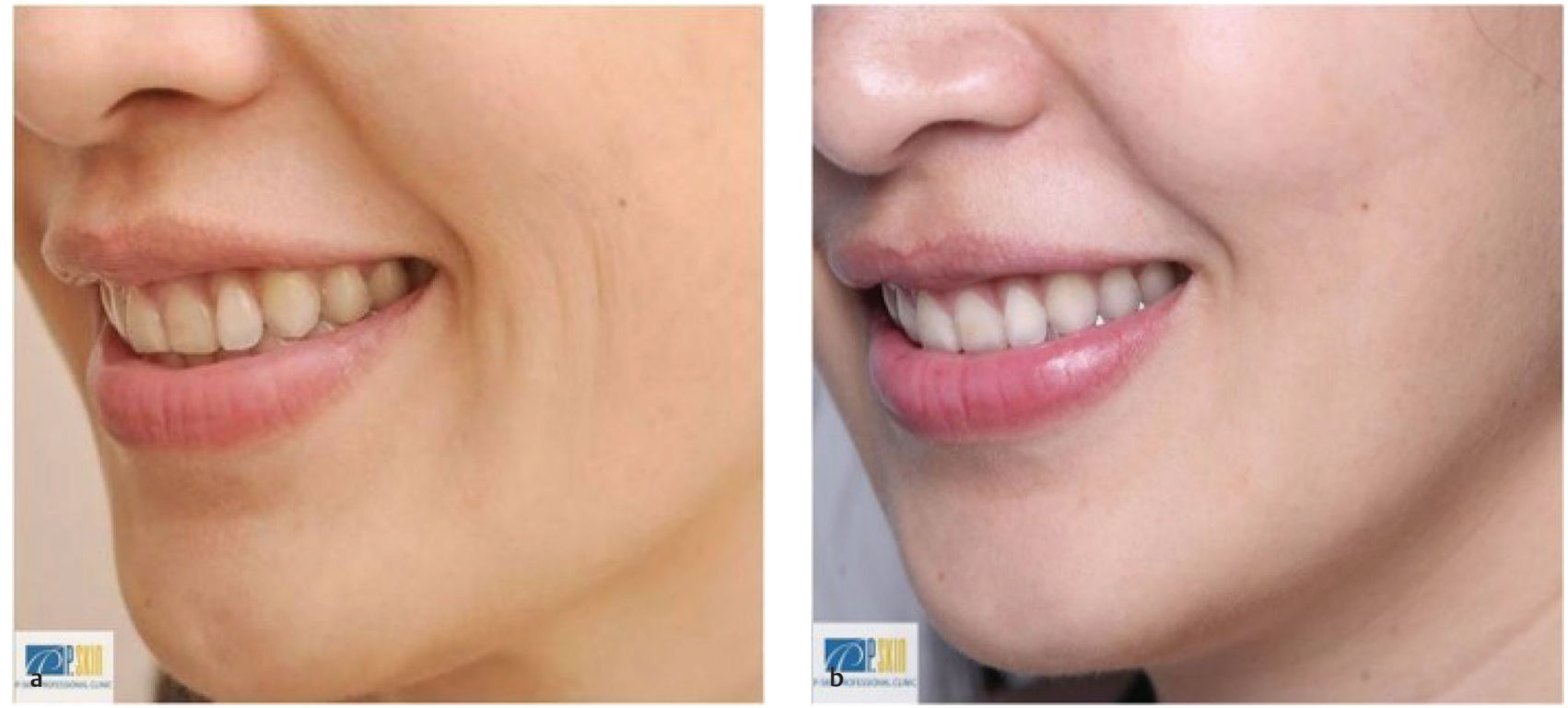

Fig. 6 Dynamic radial cheek lines. (a) Before treatment. (b) One month after $0.3 \mathrm{~mL}$ of VYC-17.5L HA (Juvéderm Volift, Allergan) per side with $25 \mathrm{G}$ cannula injection using the fanning technique.

toxin and HA filler. The glabela area is considered one of the most dangerous areas for filler injection, owing to the possibility of embolic vascular occlusion of supraorbital or supratrochlear artery of the internal carotid artery system, and the subsequent sequelae of blindness. The injection should be slow, gentle, in small amounts, and into the relatively safer plane of intradermal or superficial subdermal layers.

\section{Radial Cheek Lines ( $R C L$ )}

RCLs may appear as one of the aging signs concurrent with dynamic and static lines, and it may itself be classified as dynamic or static. - Fig. 3 (a) contains an example of static RCLs. Static and dynamic RCLs may necessitate different treatment. A study used VYC-17.5L (Juvéderm Volift, Allergan) with $25 \mathrm{G}$ cannula to treat dynamic RCLs; 53 female patients enrolled in the study, wherein a 45-day follow-up revealed improvement in $98 \%$ of cases, and significant improvement in both dynamic and static RCLs was recorded in terms of roughness, amplitude, and texture. ${ }^{20}$ Although the term RCL was not used, another study using NASHA $20 \mathrm{mg}$ or $12 \mathrm{mg}$ with 30G needle, deposited using the serial micropuncture technique, also showed improvement of dynamic RCLs within its patient population. ${ }^{10}$

\section{Author Preference}

For dynamic RCLs, based on clinical experience, the author prefers VYC-17.5L HA or VYC-15L HA. - Fig. 6 shows a case of dynamic RCLs treated with VYC-17.5L HA. This particular patient also received a combination treatment with microbotulinum toxin A (Onabotulinum toxin A) at the intradermal layer, $1 \mathrm{U}$ in $0.05 \mathrm{~mL}$ divided into five injection points, which is shown in - Fig. 7. - Fig. 8 shows another patient with dynamic RCLs, who underwent treatment with VYC-15L HA using 25G cannula and the fanning technique (-Table 5).

\section{Improvement in Skin Quality}

As previously discussed, the aging skin may alter the mechanical properties of the skin through the loss of collagen, elastin, and ground substances, and may cause the deterioration of skin quality through dryness, thinning, loss of elasticity, and line and wrinkle formation. A 2007 study demonstrated that cross-linked HA filler injections in vivo stimulates new 
collagen production in photoaged human skin. Collagen production was found to be related to the stretching of fibro-

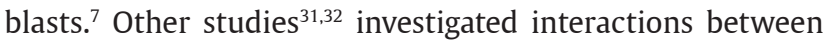
injected NASHA, fibroblasts, and the extracellular matrix in aged skin; injected NASHA was shown to enhance structural support of the extracellular matrix, resulting in fibroblast elongation, subsequent increase in procollagen I and collagens I and III production, and an increase keratinocyte and fibroblast proliferation. The net result was overall epidermal thickening and the formation of new dermal vasculature.

The recommended protocol for improving skin quality is NASHA $20 \mathrm{mg}$ or $12 \mathrm{mg}$ injected monthly for three sessions, which can retain efficacy for up to 6 months. This kind of injection treatment can significantly improve skin surface roughness and skin elasticity 4 months after the final injection session. ${ }^{33} \mathrm{~A}$ 30G needle using serial puncture technique is preferred to spread out the filler over a larger area. Clinical results indicate not only the hydration effects

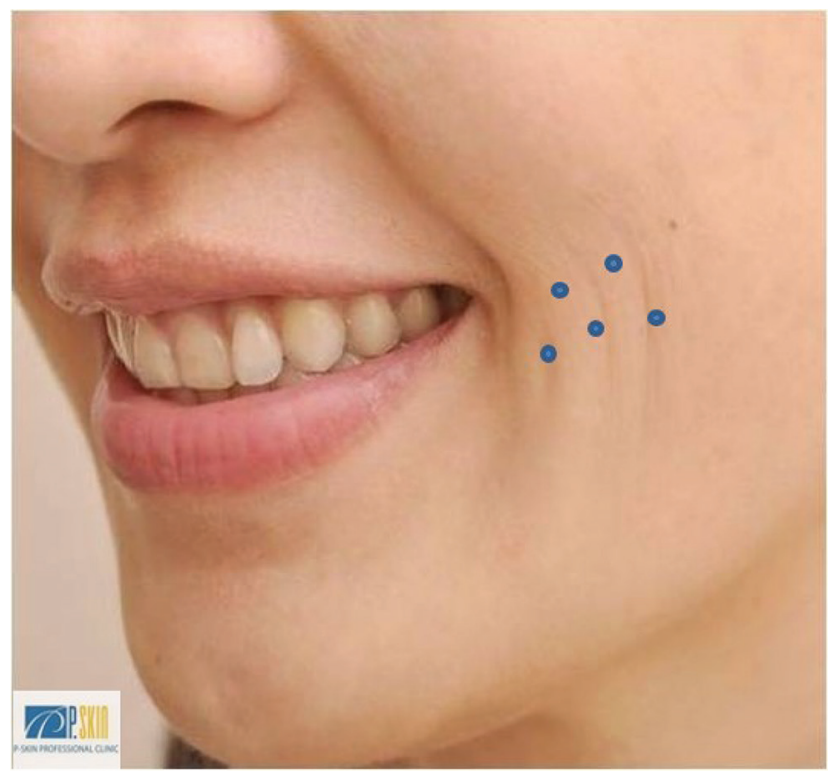

Fig. 7 Microbotulinum toxin injection points. of HA filler, but also new collagen formation ${ }^{10}$ and overall quality improvement. This holistic approach has been called the "Skinbooster" treatment. Other studies have found evidence of objective skin quality improvement after using a new cross-linked injectable product (VYC-12 HA; Juvéderm Volite, Allergan) via digital photographic analysis., ${ }^{11,12}$ This quality improvement effect can last up to 6 months, and the hydration retention effect can last for as long as 9 months after a single injection treatment.

\section{Author Preference}

For skin quality improvement, the author prefers to inject in the deep intradermal to superficial subdermal layer, with $32 \mathrm{G}$ needles. Each injection should deposit approximately $0.02-0.025 \mathrm{~mL}$ of product, for a total of 40 to 50 injections per 1 syringe of HA for each side of the cheek. Each injection should be approximately $1-1.5 \mathrm{~cm}$ apart. - Fig. 9 displays the relevant injection markings for this protocol, and - Table 6 summarizes the author's recommended technique.

One thing to keep in mind when injecting for skin quality is the depth of the injection; overly superficial

Table 5 Author preference for the treatment of radial cheek lines

\begin{tabular}{|l|l|}
\hline Items & Suggestion \\
\hline $\begin{array}{l}\text { Type of HA } \\
\text { product }\end{array}$ & $\begin{array}{l}\text { Vycross } 17.5 \mathrm{mg} / \mathrm{mL} \text { HA; VYC-17.5L } \\
\text { (Juvéderm Volift, Allergan) Vycross } 15 \mathrm{mg} / \mathrm{mL} \\
\text { HA; VYC-15L (Juvéderm Volbella, Allergan) }\end{array}$ \\
\hline Injection layer & Superficial subdermal injection \\
\hline Injection tool & $25 G 3.8 \mathrm{~mm}$ cannula \\
\hline $\begin{array}{l}\text { Injection } \\
\text { technique }\end{array}$ & Fanning \\
\hline $\begin{array}{l}\text { Injection } \\
\text { amount }\end{array}$ & $0.25-0.5 \mathrm{~mL}$ per side of cheek \\
\hline Note & $\begin{array}{l}\text { Molding after injection for better filler-tissue } \\
\text { integration. }\end{array}$ \\
\hline
\end{tabular}

Abbreviation: HA, hyaluronic acid.
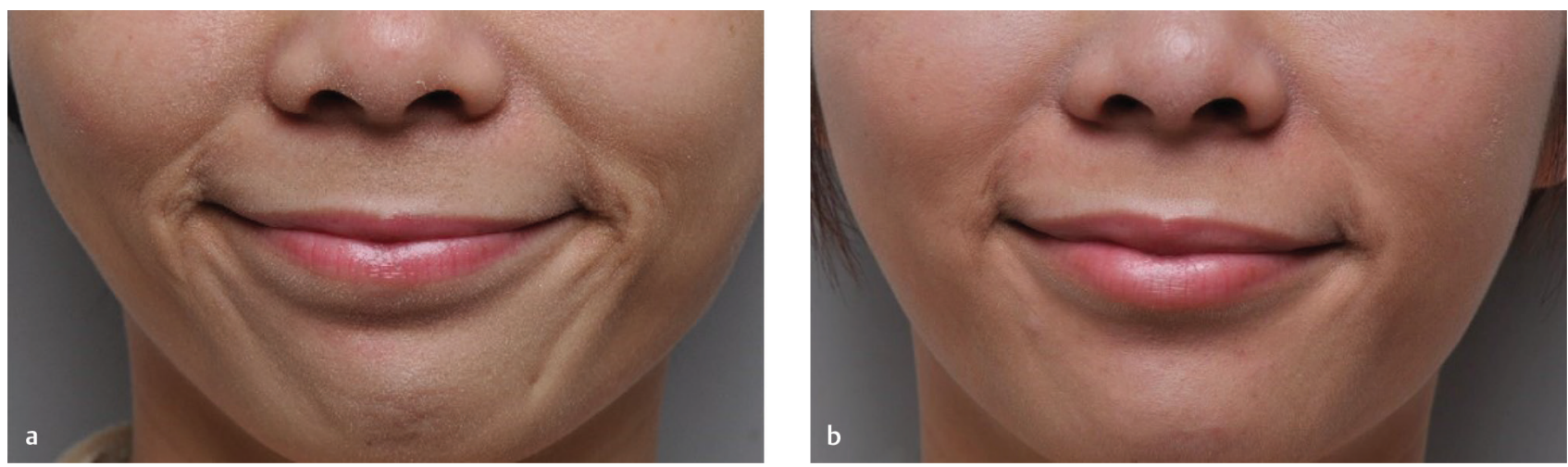

Fig. 8 Dynamic radial cheek lines (a) Before treatment. (b) One month after treatment with $0.5 \mathrm{~mL}$ VYC-15L HA (Juvéderm Volbella, Allergan) per side with $25 \mathrm{G}$ cannula, using the fanning technique. 


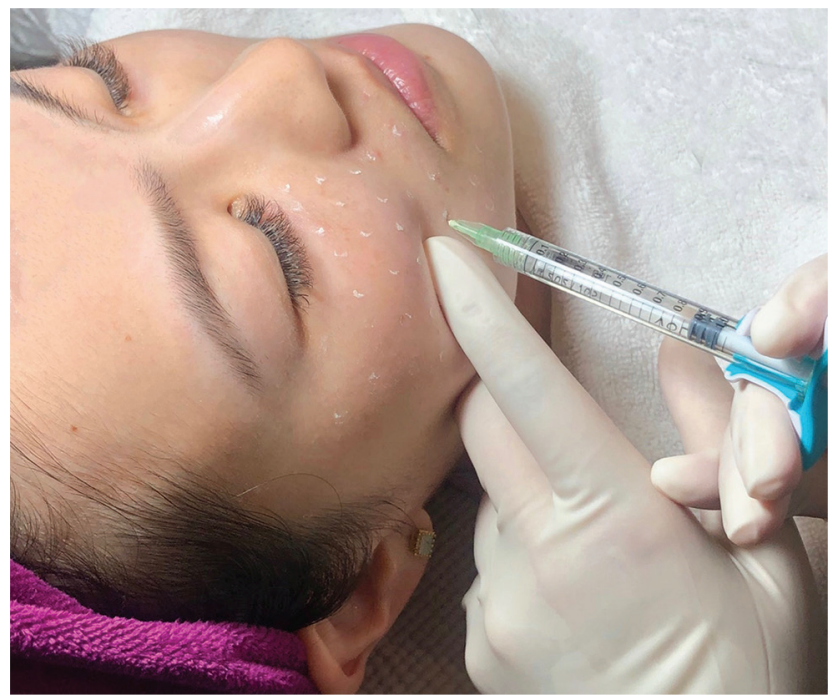

Fig. 9 Marking and injection.

Table 6 Author's preference for improving overall skin quality

\begin{tabular}{|l|l|}
\hline Items & Suggestion \\
\hline Type of HA product & VYC-12 HA, (Juvéderm Volite, Allergan) \\
\hline Injection layer & $\begin{array}{l}\text { Deep intradermal to superficial subdermal } \\
\text { layer }\end{array}$ \\
\hline Injection tool & $\begin{array}{l}32 \mathrm{G} \text { needle; change needle after } 20-25 \\
\text { injections }\end{array}$ \\
\hline Injection technique & Microdroplet(micro-aliquot) \\
\hline Injection amount & $\begin{array}{l}0.02-0.025 \text { mL per injection (40-50 injec- } \\
\text { tions per cheek) }\end{array}$ \\
\hline Note & $\begin{array}{l}\text { Molding with cotton stick is recom- } \\
\text { mended immediately after the injection of } \\
\text { one cheek }\end{array}$ \\
\hline
\end{tabular}

Abbreviation: HA, hyaluronic acid.

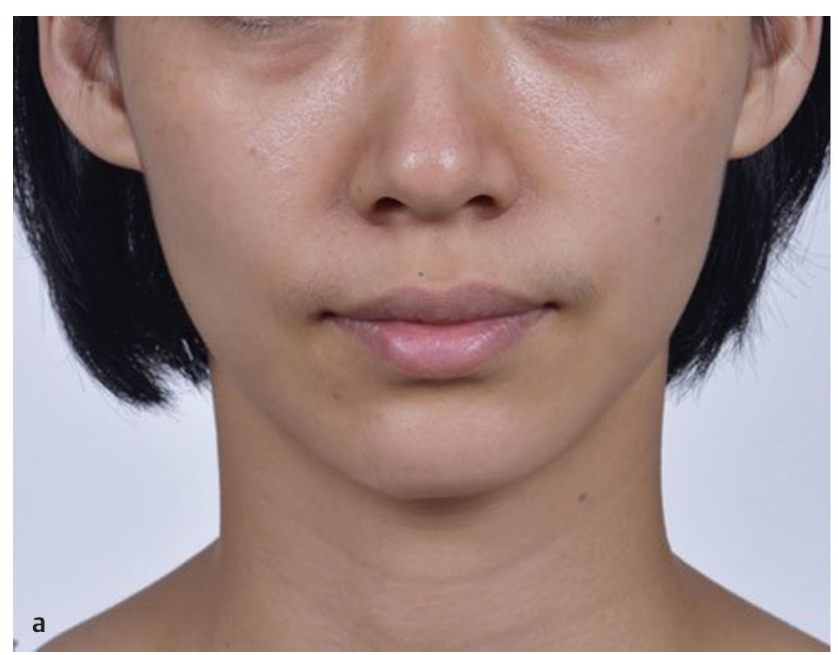

Fig. 10 A typical case of all-round improvement achieved through HA filler injection. (a) Before treatment. (b) One month after treatment. The improvement in skin quality could be seen and felt through physical examination of the skin. Surprisingly, the tear trough deformity also presented improvements. Abbreviation: HA, hyaluronic acid.

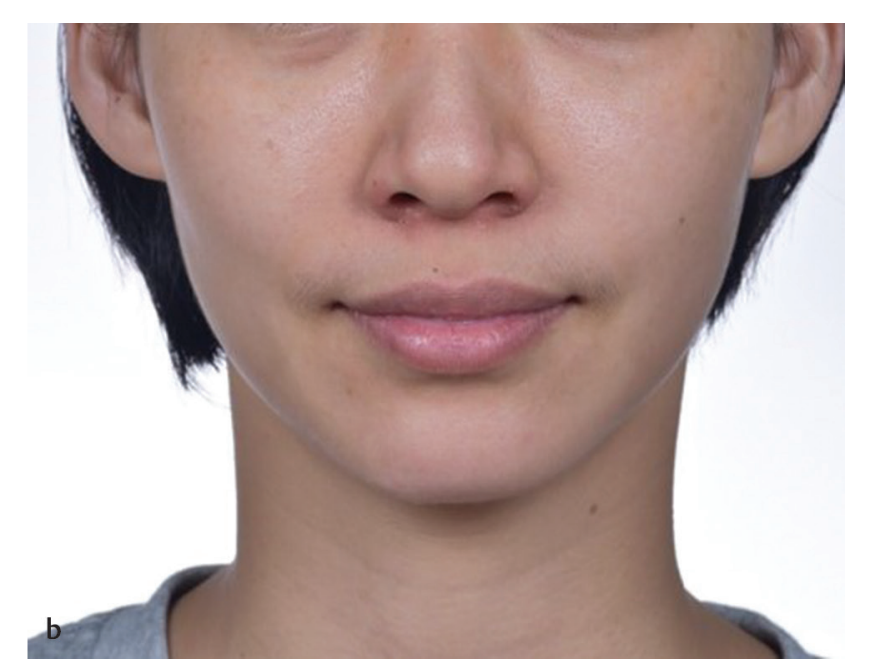

injections can create persistent papules visible under the skin, which will last for as long as the HA filler is present. Immediately after each injection, massaging or molding with a cotton stick is recommended. Since the eyelid has the thinnest skin in the body, it is recommended to halve the usual injection dose (0.01-0.015 mL per injection). The typical amount of injection for each cheek is $1 \mathrm{~mL}(1$ syringe). If the forehead or neck is indicated, another 1 to $2 \mathrm{~mL}$ is recommended for better results. - Fig. 10 shows a typical case of all-round improvement achieved through HA filler injection. The improvement in skin quality could be seen and felt through physical examination of the skin. This kind of injection can also improve transverse neck lines (also known as "necklace lines") by using $15 \mathrm{mg}$ or 12 mg Vycross HA. - Fig. 11 shows a case with necklace lines treated with $15 \mathrm{mg}$ Vycross HA using serial puncture and linear injection techniques.

\section{Conclusions}

There is abundant literature support for the efficacy and wide-ranging applications of HA filler injection for a variety of aesthetic skin issues, in particular static lines, RCLs, and improvement of skin quality. For static lines, VYC-15L ([Juvéderm Vobella, Allergan] with lidocaine) in the superficial dermal layer deposited through the serial puncture method has proven to be effective. For RCLs, VYC-15L or 17.5L combined with botulinum toxin in the superficial epidermal layer has proven to be effective. For skin quality improvement, 40 to 50 injections of VYC-12L ([Juvéderm Volite, Allergan] with lidocaine), deposited in the superficial subdermal layer, has proven to be effective. In general, for the best efficacy, HA injections for specific skin conditions should differ in depth, product, technique, and amount. 

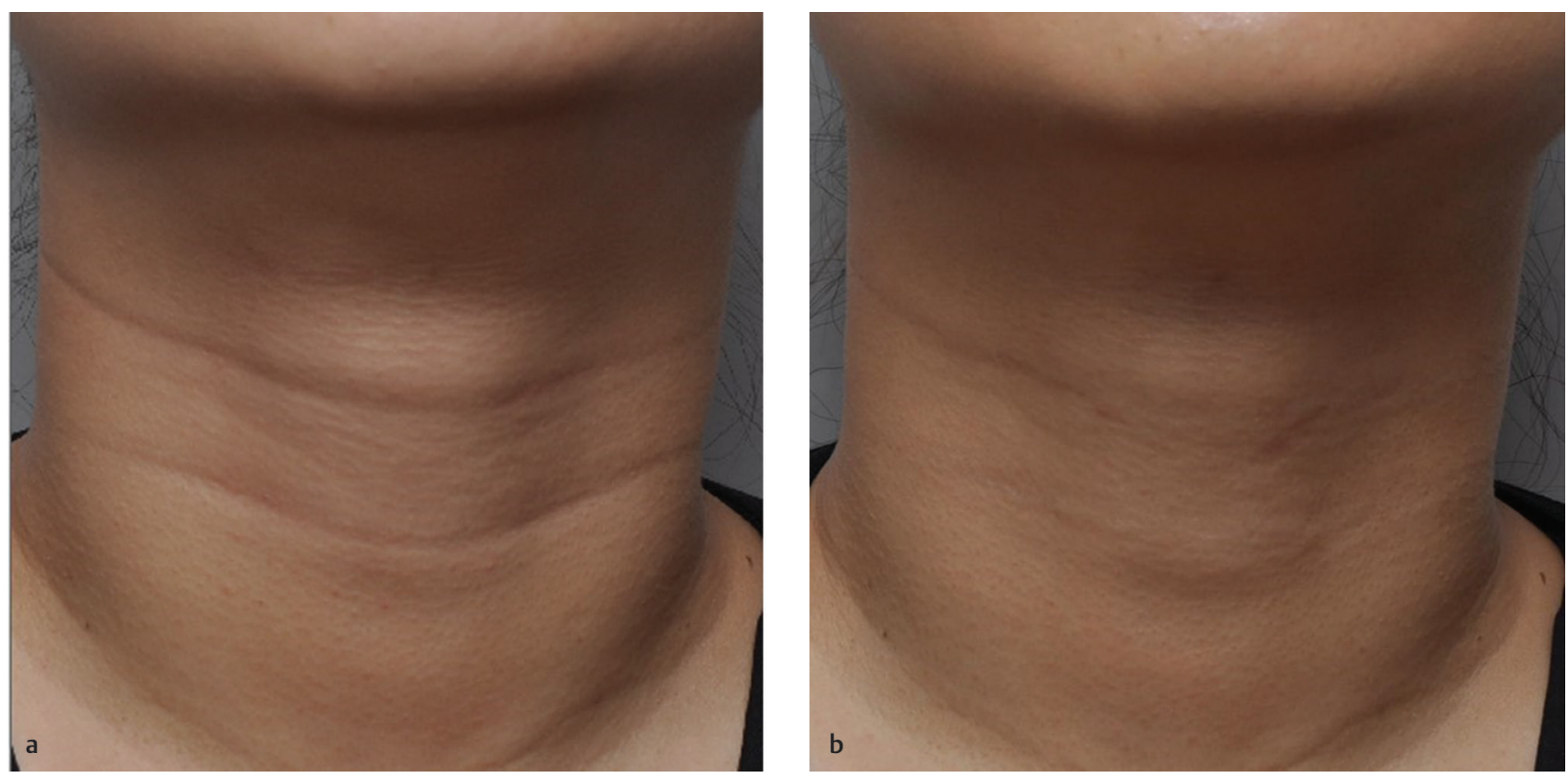

Fig. 11 Transverse neck lines. (a) Before treatment. (b) One month after injection with $1 \mathrm{~mL}$ VYC-15L HA (Juvéderm Volbella, Allergan) with needle, using the serial puncture linear threading technique.

\section{Conflicts of Interest}

None declared.

\section{References}

1 Mendelson B, Wong $\mathrm{CH}$. Changes in the facial skeleton with aging: implications and clinical applications in facial rejuvenation. Plast Reconstr Surg 2008;121(6):2107-2112

2 Rohrich RJ, Pessa JE, Ristow B. The youthful cheek and the deep medial fat compartment. Aesthetic Plast Surg 2012;36(4):753-760

3 Gierloff M, Stöhring C, Buder T, Gassling V, Açil Y, Wiltfang J. Aging changes of the midfacial fat compartments: a computed tomographic study. Plast Reconstr Surg 2012;129(1):263-273

4 Saluja SS, Fabi SG. A holistic approach to antiaging as an adjunct to antiaging procedures: a review of the literature. Dermatol Surg 2017;43(4):475-484

5 Alghoul M, Codner MA. Retaining ligaments of the face: review of anatomy and clinical applications. Aesthet Surg J 2013;33(6):769-782

6 Kim HJ, Seo KK, Lee HK, Kim J., Clinical Anatomy of the Face for Filler and botulinum toxin injection Springer; 2016

7 Wang F, Garza LA, Kang S, et al. In vivo stimulation of de novo collagen production caused by cross-linked hyaluronic acid dermal filler injections in photodamaged human skin. Arch Dermatol 2007;143(2):155-163

8 de Almeida AT, Figueredo V, da Cunha ALG, et al. Consensus recommendations for the use of hyperdiluted calcium hydroxyapatite (Radiesse) as a face and body biostimulatory agent. Plast Reconstr Surg Glob Open 2019;7(3):e2160

9 Bohnert K, Dorizas A, Lorenc P, Sadick NS. Randomized, controlled, multicentered, double-blind investigation of injectable Poly-L-Lactic Acid for improving skin quality. Dermatol Surg 2019;45(5):718-724

10 Landau M, Fagien S. Science of hyaluronic acid beyond filling: fibroblasts and their response to the extracellular matrix. Plast Reconstr Surg 2015;136(5(Suppl):188S-195S

11 Cavallini M, Papagni M, Ryder TJ, Patalano M. Skin quality improvement with VYC-12, a new injectable hyaluronic acid: objective results using digital analysis. Dermatol Surg 2019;45(12):1598-1604

12 Niforos F, Ogilvie P, Cavallini M, et al. VYC-12 injectable gel is safe and effective for improvement of facial skin topography: a prospective study. Clin Cosmet Investig Dermatol 2019;12:791-798

13 França Wanick FB, Almeida Issa MC, Luiz RR, Soares Filho PJ, Olej B. Skin remodeling using hyaluronic acid filler injections in photo-aged faces. Dermatol Surg 2016;42(3):352-359

14 Greco TM, Antunes MB, Yellin SA. Injectable fillers for volume replacement in the aging face. Facial Plast Surg 2012;28(1):8-20

15 Wollina U. Facial rejuvenation starts in the midface: three-dimensional volumetric facial rejuvenation has beneficial effects on nontreated neighboring esthetic units. J Cosmet Dermatol 2016;15(1):82-88

16 Salti G, Rauso R. Facial rejuvenation with fillers: the dual plane technique. J Cutan Aesthet Surg 2015;8(3):127-133

17 Rho NK, Chang YY, Chao YY, et al. Consensus recommendations for optimal augmentation of the Asian face with hyaluronic acid and calcium hydroxylapatite fillers. Plast Reconstr Surg 2015;136(5):940-956

18 Peng PH, Peng JH. Treating the tear trough: A new classification system, a 6-step evaluation procedure, hyaluronic acid injection algorithm, and treatment sequences. J Cosmet Dermatol 2018;17(3):333-339

19 Fagien S, Cassuto D. Reconstituted injectable hyaluronic acid: expanded applications in facial aesthetics and additional thoughts on the mechanism of action in cosmetic medicine. Plast Reconstr Surg 2012;130(1):208-217

20 Ogilvie P, Fink B, Leys C, et al. Improvement of radial cheek lines with hyaluronic acid-based dermal filler VYC-17.5L: results of the BEAM Study. Dermatol Surg 2020;46(3):376-385

21 Kim JS. Changes in dermal thickness in biopsy study of histologic findings after a single injection of polycaprolactone-based filler into the dermis. Aesthet Surg J 2019;39(12):NP484-NP494

22 Bukhari SNA, Roswandi NL, Waqas M, et al. Hyaluronic acid, a promising skin rejuvenating biomedicine: A review of recent updates and pre-clinical and clinical investigations on cosmetic 
and nutricosmetic effects. Int J Biol Macromol 2018;120(Pt B) :1682-1695

23 Kontis TC, Lacombe VG, Cosmetic Injection Techniques, 2nd ed. Thieme; 2019

24 Bartus CL, Sattler G, Hanke CW. The tower technique: a novel technique for the injection of hyaluronic acid fillers. J Drugs Dermatol 2011;10(11):1277-1280

25 unknown[], de Maio M. Unlocking the code to facial revitalization: A step-by-step approach to using injectables with the MD Codes. Produced and funded by Allergan 2017

26 Micheels P, Sarazin D, Besse S, Sundaram H, Flynn TC. A blanching technique for intradermal injection of the hyaluronic acid Belotero. Plast Reconstr Surg 2013;132(4(Suppl 2) :59S-68S

27 Farage MA, Miller KW, Maibach HI, Textbook of Aging Skin, Springer; 2010

28 Krueger N, Luebberding S, Oltmer M, Streker M, Kerscher M. Age-related changes in skin mechanical properties: a quantitative evaluation of 120 female subjects. Skin Res Technol 2011;17(2):141-148
29 Mayes AE, Murray PG, Gunn DA, et al. Ageing appearance in China: biophysical profile of facial skin and its relationship to perceived age. J Eur Acad Dermatol Venereol 2010;24(3):341-348

30 Benedetto AV, Botulinum Toxins in Clinical Aesthetic Practice, 3rd ed. CRC Press, Taylor \& Francis Group; 2018

31 Quan T, Wang F, Shao Y, et al. Enhancing structural support of the dermal microenvironment activates fibroblasts, endothelial cells, and keratinocytes in aged human skin in vivo. J Invest Dermatol 2013;133(3):658-667

32 Turlier V, Delalleau A, Casas C, et al. Association between collagen production and mechanical stretching in dermal extracellular matrix: in vivo effect of cross-linked hyaluronic acid filler. A randomised, placebo-controlled study. J Dermatol Sci 2013;69(3):187-194

33 Kerscher M, Bayrhammer J, Reuther T. Rejuvenating influence of a stabilized hyaluronic acid-based gel of nonanimal origin on facial skin aging. Dermatol Surg 2008;34(5):720-726 